\title{
New Bouguer Anomaly Map for the Territory of the Slovenia
}

\author{
Klemen Medved ${ }^{1,2, *(D)}$, Oleg Odalović ${ }^{3}(\mathbb{D})$ and Božo Koler ${ }^{2}(\mathbb{D}$ \\ 1 Surveying and Mapping Authority of the Republic of Slovenia, Zemljemerska Ulica 12, \\ 1000 Ljubljana, Slovenia \\ 2 Faculty of Civil and Geodetic Engineering, University of Ljubljana, Jamova Cesta 2, 1000 Ljubljana, Slovenia; \\ Bozo.Koler@fgg.uni-lj.si \\ 3 Department of Geodesy and Geoinformatics, Faculty of Civil Engineering, University of Belgrade, \\ Bulevar Kralja Aleksandra 73, 11000 Belgrade, Serbia; odalovic@grf.bg.ac.rs \\ * Correspondence: klemen.medved@gov.si; Tel.: +386-1-4784854
}

Citation: Medved, K.; Odalović, O.; Koler, B. New Bouguer Anomaly Map for the Territory of the Slovenia. Remote Sens. 2021, 13, 4510. https:// doi.org/10.3390/rs13224510

Academic Editor: Guillaume Ramillien

Received: 19 October 2021

Accepted: 6 November 2021

Published: 10 November 2021

Publisher's Note: MDPI stays neutral with regard to jurisdictional claims in published maps and institutional affiliations.

Copyright: (c) 2021 by the authors. Licensee MDPI, Basel, Switzerland. This article is an open access article distributed under the terms and conditions of the Creative Commons Attribution (CC BY) license (https:// creativecommons.org/licenses/by/ $4.0 /)$.

\begin{abstract}
The existing Bouguer anomaly map, which covers the territory of the Republic of Slovenia is a few decades old. Since then, quite a few new gravimetric measurements (data) for the territory of Slovenia as well as high quality digital terrain models that are needed for creating such a map have been made available. The methodology and standards for creating gravity anomaly maps are also changing. Thus, the national Bouguer anomaly map was updated. There were some gross errors detected in the set of old gravimetric data. Additionally, the influence of new updated gravimetric data was analyzed. The comparison of the various maps and the analysis of the influence of input gravimetric data indicates that the new gravimetric data of Slovenia has a significant influence on the creation of the gravimetric anomaly maps for Slovenia (even over $30 \mathrm{mGals}$ at some points).
\end{abstract}

Keywords: Bouguer anomaly; gravity anomalies; gravimetric data; anomaly maps; Slovenia

\section{Introduction}

The Bouguer anomaly map is used in geological and geophysical research. Slovenia currently uses a Bouguer anomaly map that was created during the second half of the previous century. This map was created from the data obtained from a gravimetric survey carried out in the former Yugoslavia, within which the survey of the territory of Slovenia was performed in several measurements between 1952 and 1965, all of which used the Potsdam gravimetric system. In 1996, Slovenia started establishing a new fundamental gravimetric network (based on the IGSN71 gravimetric system) that is used as the base in all contemporary gravimetric observations [1]. Thus, numerous high quality gravimetric measurements have been recently performed for the territory of Slovenia, mainly with the intention of establishing a new national height system and calculating the new height reference system (geoid or quasi-geoid model). Gravimetric data for neighboring countries have also been acquired and used in the creation of the new geoid model, and consequently, also a Bouguer anomaly map for the territory of Slovenia.

Before the Slovene declaration of independence, Bouguer anomaly maps were created for the entire territory of the former Yugoslavia (SFRY). In 1972, the Federal Geological Society from Belgrade (in cooperation with other institutions) published the 'Gravimetric Map of SFR Yugoslavia: Bouguer anomalies at a scale 1:500,000'. This map was based on regional and detailed gravimetric measurements of the territory of Slovenia and the four neighboring countries made in the 1950s and 60s [2]. The Bouguer anomaly map for the territory of Slovenia was based on old Yugoslav gravimetric data, obtained between 1956 and 1965 and created in 1967 [3], and additionally interpolated and digitalized between 1996 and 2000 [4]. The survey of the territory of the Republic of Slovenia was performed by the Geological Survey Ljubljana (today known as the Geological Survey of Slovenia). Approximately 2500 points with measured relative gravity values in the Potsdam gravimetric system were used to create the map at a scale 1:100,000. This map is shown in Figure 1a. 
This map is dominated by the strong regional influence of deeper structures, in opposition to the local or residual, which are a consequence of shallower geological structures [4]. The data for Slovenia reflect the complex structural deployment in the transition area between the Alps, the Carpathian Mountains, the Dinaric Mountains, and the Pannonian Basin. The significant differences in the thickness of the Earth's crust [5] and the depth of the sedimental basins in the transition area between the Alps and the Dinaric Mountains with the Pannonian Basin are clearly depicted in the Bouguer anomaly map of Slovenia.

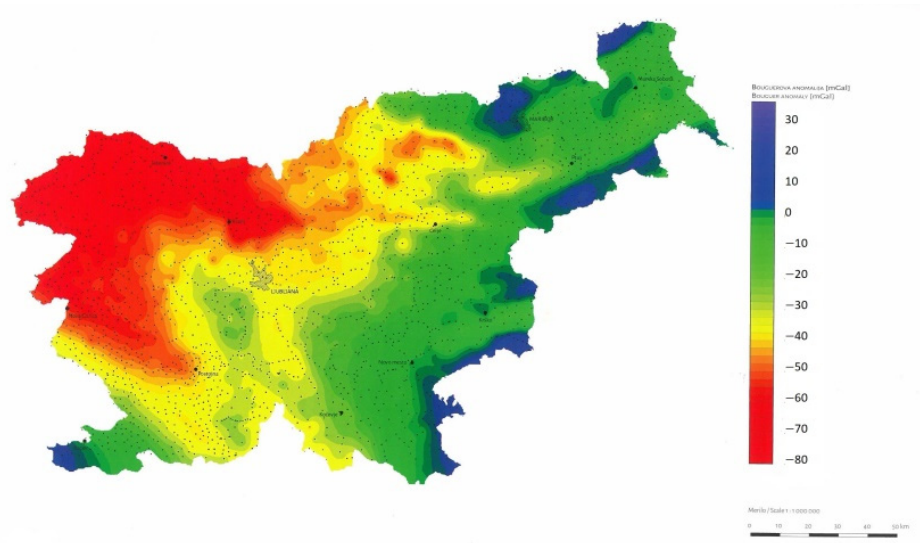

(a)

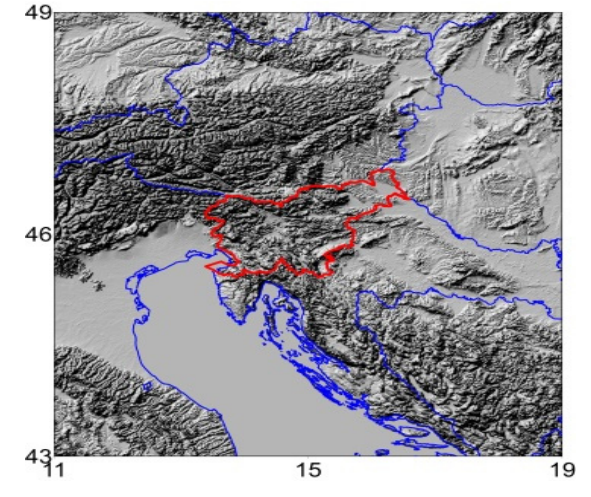

(b)

Figure 1. (a) Bouguer anomaly map for Slovenia [4]; (b) DTM of Slovenia with its surroundings-DTM1000 $\left(30^{\prime} \times 45^{\prime}\right)$.

Numerous updated national Bouguer anomaly maps are currently being created, as researchers are making the best use of the improved topographic models and the increasingly improved gravimetric data at their disposal. Various methodologies are being used [6] and several new maps have been created in the vicinity of Slovenia recently: Austria [7], Hungary [8], Italy [9], Adriatic Sea [10], Croatia [11], the pan-Alps area [12]. The existing Bouguer anomaly map for Slovenia [3] was created quite a while ago, and as has been previously stated, there are quite a few new gravimetric measurements (data) for the territory of Slovenia as well as high quality digital terrain models that are needed for creating such a map at our disposal. A detailed description of these available data is given in Section 2. Unfortunately, the recently created regional map of gravimetric anomalies, which encompasses the area of the Alps [12], failed to include the new gravimetric data for Slovenia as it only used the old data. Thus, it would make sense to update the national Bouguer anomaly map. The methodology and standards for creating gravity anomaly maps are also changing [13]. Methods of calculations and the used formulas are described in Section 3. In Section 4 (Results), different gravity anomaly maps for Slovenia are presented and a comparison of these maps with the analysis of the influence of different gravimetric data are given.

\section{Materials and Data}

\subsection{Digital Terrain Models}

There are several digital terrain models for the territory of Slovenia in the following resolutions: DTM1 $(1 \mathrm{~m} \times 1 \mathrm{~m})$, DTM25 $(25 \mathrm{~m} \times 25 \mathrm{~m})$, DTM100 $(100 \mathrm{~m} \times 100 \mathrm{~m})$, and DTM1000 $(1000 \mathrm{~m} \times 1000 \mathrm{~m})$, all of which were used in our research. DTM100 and DTM1000 were prepared to calculate the model of the quasi-geoid and were created from the original DTM25 data (for the territory of the Republic of Slovenia) and merged with SRTM-3 v2.1 (Shuttle Radar Topography Mission) data for the cross-border belt for a distance of at least $167 \mathrm{~km}$ [14]. The data merged by bi-linear interpolation were used to create detailed $(100 \mathrm{~m} \times 100 \mathrm{~m})$ and coarse $(1000 \mathrm{~m} \times 1000 \mathrm{~m})$ digital elevation models. DTM25 covers the territory within Slovenia, DTM100 covers the area between $45-47^{\circ} \mathrm{N}$, $15-17^{\circ} \mathrm{E}$, while DTM1000 covers the area $43-49^{\circ} \mathrm{N}, 11-19^{\circ} \mathrm{E}$ (Figure $1 \mathrm{~b}$ ). DTM1, with a 
spatial resolution of $1 \mathrm{~m}$, was created from the project 'Laser scanning of Slovenia' by airborne LIDAR and covers the whole territory of Slovenia.

\subsection{Gravimetric Data}

In Slovenia, there are various sets of gravimetric data at our disposal: the old gravimetric data of the former SFRY for the territory of Slovenia and a part of Croatia, gravimetric data for the border territories of the neighboring countries (Italy, Austria, and Hungary, which was acquired through formal agreements and used to calculate the new quasi-geoid of Slovenia), data from the fundamental gravimetric network, gravimetric data from the benchmarks in the leveling network of the 1st order and the data from the new regional gravimetric survey of the territory of Slovenia. All, or at least most of this data, were also used to calculate the new height reference system (i.e., the quasi-geoid model of Slovenia).

(A) Former SFRY gravimetric data covering the territory of Slovenia and part of Croatia

The data from the old gravimetric survey performed by the former SFRY reach into the 1950s. This dataset was analyzed and transformed (from the original Gauss Kruger coordinates (Bessel ellipsoid) into the ETRS89 Transversal Mercator (GRS80 ellipsoid)) using the national triangular transformation, version 3.0 [15], already in the process of calculating the new quasi-geoid. Figure 2a shows the old gravimetric data of the former SFRY for the territory of Slovenia and a part of Croatia, which are at our disposal, in blue dots. The entire set includes 6362 points, out of which 3365 are located within the territory of Slovenia, while the remaining 2997 are located in the territory of Croatia.

(B) Data for the border area with neighboring countries (Italy, Austria, and Hungary)

Gravimetric data for the border areas encompass the area outside the territory of Slovenia within the coordinates $45-47^{\circ} \mathrm{N}$ and $13-17^{\circ} \mathrm{E}$. The gravimetric data for the border area with Italy contained a set of 1402 points. It is not known when the survey took place. The original heights were measured within the Italian height system with datum Genova 1942, thus they were transformed to the height datum Trieste 1875 [16]. The gravimetric data for Austria covers the border area south of the $47^{\circ}$ parallel. The dataset consists of 3984 points. The heights refer to the height datum Trieste 1875. The gravimetric measurements were performed between 1952 and 2009. The gravimetric data for the border area with Hungary consists of 1801 points. The original heights refer to the Kronstadt height datum, thus they were transformed to the height datum Trieste 1875 [16]. The coordinates for all of the previously mentioned data refer to ETRS89 (ellipsoid GRS80), while the gravimetric values refer to IGSN71. Figure 2a shows the data for all aforementioned neighboring countries in red dots.

(C) Data of the fundamental gravimetric network of Slovenia

The fundamental gravimetric network of Slovenia consists of 36 points, six absolute gravimetric points of the network of the 0 order and 30 relative gravimetric points of the 1st order (Figure 2b). The absolute gravimetric points were stabilized in 1995 and since then, a few measurements have been carried out on them, the last one in 2014. The gravity value of the 1st order points was established with gravimetric measurements carried out with two Scintrex CG-3M relative gravimeters in 2006. The gravimetric measurements were concluded with the calculation of the appropriate reductions in the measured gravity values by adjustment of the gravimetric network through two steps. The estimated precision of the individual points ranged between $3.0 \mu \mathrm{Gal}$ and $6.2 \mu \mathrm{Gal}$ [17]. The newly calculated fundamental gravimetric network was also compared to the old Potsdam datum, in which all of the previous gravimetric surveys in Slovenia were carried out, and the transformation between the Potsdam and IGSN71 systems was ascertained [18]. The new fundamental gravimetric network of the Republic of Slovenia represents a solid base for all future gravimetric surveys to be carried out on the territory of Slovenia and defines the national gravimetric datum GD06. 




(a)

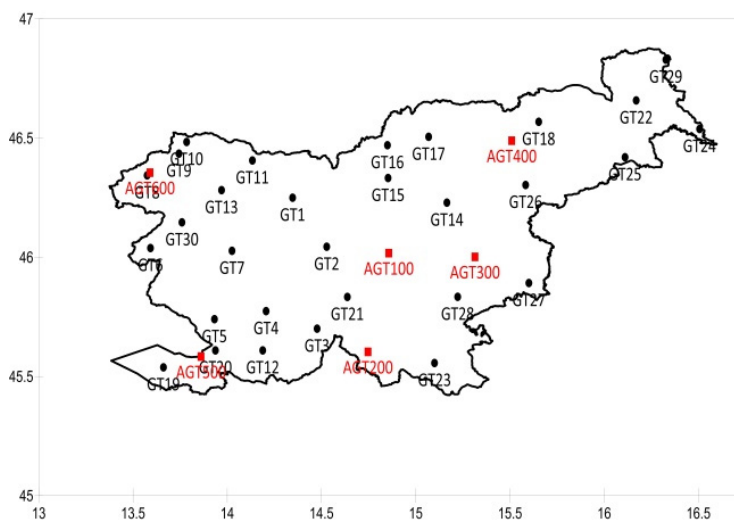

(b)

Figure 2. (a) Gravimetric data of the former SFRY for the territory of Slovenia and parts of Croatia (blue dots) and gravimetric data for Italy, Austria, and Hungary (red dots); (b) Fundamental gravimetric network of Slovenia (six absolute and 29 relative points of the 1st order).

\section{(D) Gravimetric data of the benchmarks of the 1st order leveling network}

For the needs of implementing the new height system (assigned as SVS2010), which in practice means the calculation of geopotential numbers on benchmarks, gravimetric measurements were performed on approximately $85 \%$ of all benchmarks of the 1 st order leveling network [19]. This was performed simultaneously with the leveling measurements (between 2006 and 2016) taken with two relative Scintrex gravimeters (models CG-3M and CG5). The estimated accuracy of the performed measurements was $\pm 50 \mu \mathrm{Gals}$. The set consisted of 2054 points. All gravity measurements refer to the national gravimetric datum GD06 (in IGSN71). Figure 3a shows all points (benchmarks) on which the gravimetric measurements were performed.

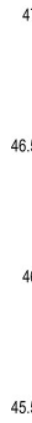

46.5 ${ }_{13}^{45}$

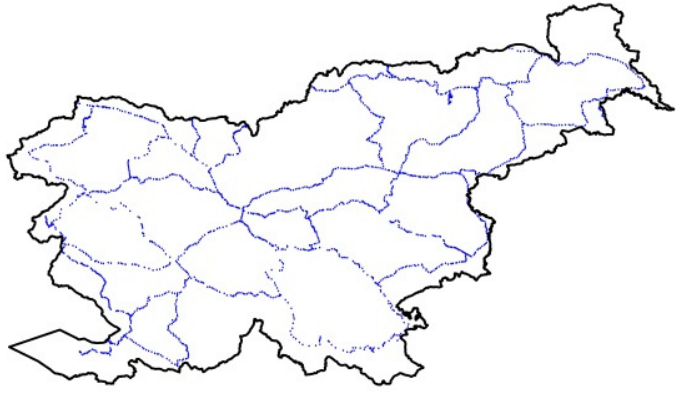

(a)

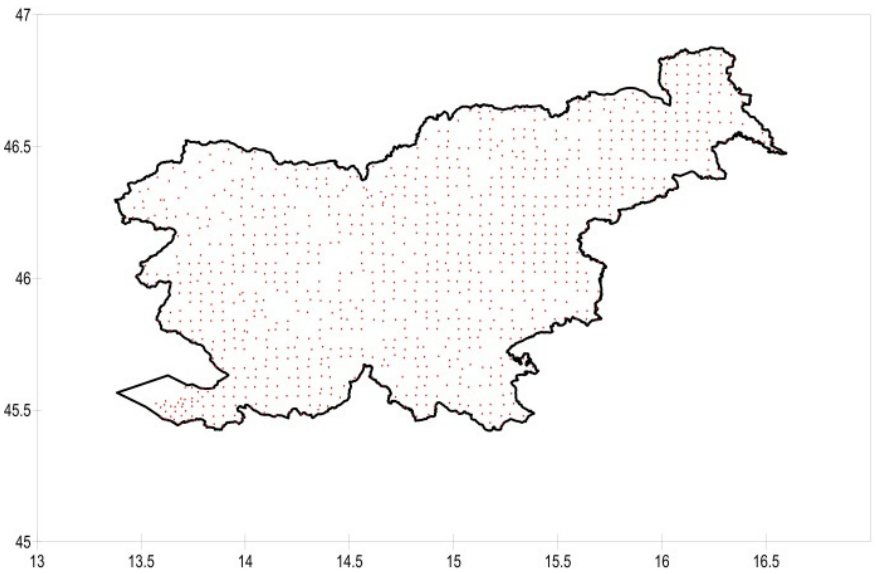

(b)

Figure 3. (a) Gravimetric measurements performed on the leveling network of Slovenia-1st order benchmarks; (b) Regional gravimetric measurement of Slovenia.

(E) Data from the new regional gravimetric survey of Slovenia

To calculate the new height reference system (geoid or quasi-geoid), regional gravimetric measurements were performed in Slovenia. Prior to this, an analysis of the density of the existing gravimetric points measured in the post 2006 period was performed in order to define the geopotential numbers on benchmarks. Based on this, a proposal for the densification in areas with an insufficient density of points was initiated [20]. With this, the entire area of the country became covered with high quality gravimetric points in a grid of at least $4 \mathrm{~km} \times 4 \mathrm{~km}$, while in the area of the Slovene coast, the grid was densified to a cell 
size of $2 \mathrm{~km} \times 2 \mathrm{~km}$ (Figure 3b). The survey took place between 2014 and 2019, at which all measurements refer to the national gravimetric datum GD06 (IGSN71). The estimated accuracy was $\pm 30 \mu \mathrm{Gals}$. The coordinates of all measured detailed points were determined by GNSS measurements (RTK or static method).

\subsection{Analyzing the Quality of the 'Old' Yugoslav Gravimetric Data}

When evaluating the quality of gravimetric data, one needs to pay special attention to the data from the old SFRY gravimetric survey carried out on the territory of Slovenia and a part of Croatia. As previously stated, the data from the old SFRY gravimetric survey originates from the 1950s to 70s, while some gravimetric surveys of higher orders are of an even older date. The archive documentation [2], which describes the procedures in which the gravimetric surveys were performed in SFRY, leads to the conclusion that in most cases, characteristic objects were selected to determining the position of points from the topographic maps at a scale 1:50,000 or 1:25,000. These gravimetric points were defined in accordance with that times' possibilities. In detailed gravimetric surveys, the position was determined with the use of polygons (including compass ones) or by measuring the distance from the gravimetric point to the selected object, the position of which was defined on the topographic maps. Polygons were linked either to a trigonometric network, or to points with known positions. The heights were determined with the use of approximate methods. As we did not have access to the original survey data, it is hard to evaluate the quality of the gravimetric measurements, however, their position/height precision can be verified. All the data from the old SFRY gravimetric survey for the territory of Slovenia were compared with the digital terrain model DTM1 (see Section 2.1), which means that the heights of the original coordinates of the gravimetric points were compared with the appropriate heights on the DTM1. This enabled us to calculate the deviations (differences) between the two heights for each gravimetric point. However, we did not know whether the deviation was a consequence of the missed height or the missed horizontal coordinate of the individual point. Figure 4 a shows the deviations for individual points within the territory of Slovenia.

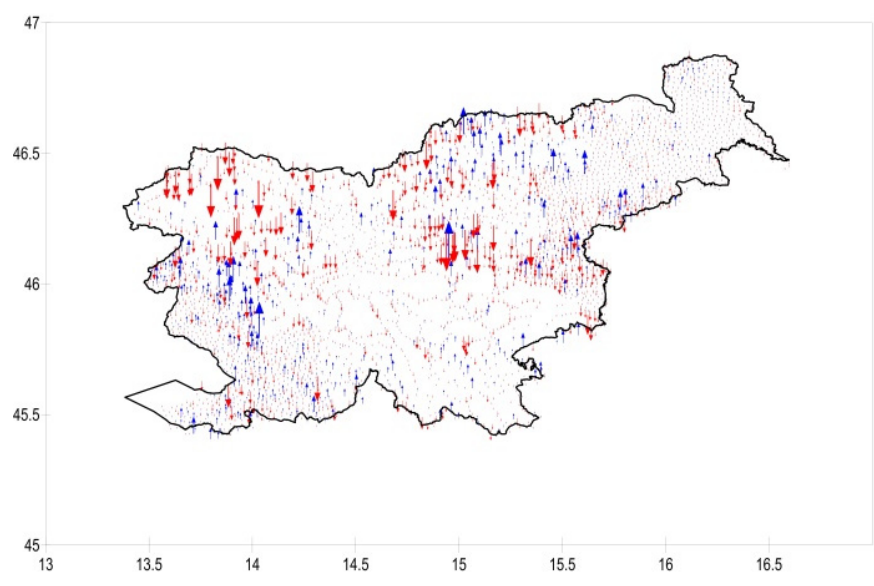

(a)



(b)

Figure 4. (a) Height deviations based on DTM analysis; (b) Height deviations after the filtering.

The deviations are shown as a difference between the 'original height' minus the 'DTM height'. At first glance, it seems that the deviations were the largest in N and NW Slovenia, especially in the mountainous areas. On average, the deviations in NE and S Slovenia were smaller. It is likely that the measurements were performed in individual clusters and the method for defining the coordinates was linked to this, however, we currently do not have any data related to this. The statistic indicators of this analysis are gathered in Table 1. 
Table 1. Statistical indicators of height analysis on the A: Set of Yugoslavian gravimetric data, B: Set of measured benchmarks, and C: Set of filtered Yugoslav data.

\begin{tabular}{cccc}
\hline Statistical Indicators & A: Set of SFRY Data & B: Set of Benchmarks & C: Set of Filtered SFRY Data \\
\hline No. of points & 3364 & 2054 & 2975 \\
Min [m] & -390.94 & -22.72 & -68.65 \\
Max [m] & 333.14 & 14.45 & 68.92 \\
Mean [m] & -7.10 & 0.58 & -2.29 \\
Median [m] & -0.42 & 0.73 & -0.18 \\
St. Dev. [m] & 51.25 & 2.38 & 23.51 \\
\hline
\end{tabular}

The statistical indicators of the analysis show that the original height, and consequentially, the position of some points, is extremely questionable. The deviations range from a minimum of $-391 \mathrm{~m}$ to a maximum of $+333 \mathrm{~m}$ (see Table 1, column A). Consequentially, these data needed to be eliminated from further calculations in certain cases. As deviations were quite equally distributed in both directions (positive and negative, see Figure $4 \mathrm{a}$ where there is a normal distribution of deviations (statistical $p$-value $<0.05$ in "Goodness-Of-Fit Test for Normality"), it shows that there was no systemic shift or error that would have caused such deviations. Thus, the decision was made to filter the data accordingly and use only data for which it can be safely assumed that it does not contain significant errors for future procedures. To define the criteria for eliminating or filtering data, a similar analysis was performed on a set of quality determined benchmarks, the height of which was defined by the leveling method (see Section 2.2: D). Their horizontal position was defined in numerous ways; in some cases, it is also taken from a map or a digital orthophoto, which is why deviations are also expected. The statistical results of this analysis (comparison of the benchmark heights on DTM1) are shown in Table 1, column B. The results of this dataset, which included 2054 points, were expectedly better. The minimum deviation by height was $-23 \mathrm{~m}$ and maximum was $+14 \mathrm{~m}$. If we assume that the coordinates of these points are qualitatively defined, we take points with a triple value of the maximum deviation as the criterion for elimination (filtering). This helps to eliminate the coarsely displaced points. The criterion is thus $3 \times 22 \mathrm{~m}$, which is rounded up to $\pm 70 \mathrm{~m}$ and is set extremely loosely. If we took three times the value of the standard deviation $(3 \times 2.4 \mathrm{~m})$ as the criterion, it would eliminate too many points, thus making it impossible to perform further analysis.

Therefore, all points that deviated by more than $\pm 70 \mathrm{~m}$ in height from the set of the old Yugoslav gravimetric data were eliminated, which included 3365 points for the territory of Slovenia. With this, 390 coarsely erroneous points were eliminated, while 2975 points remained in the filtered set (Figure $4 \mathrm{~b}$ ). Table 1 (column C) shows the statistical indicators that remained once the set of Yugoslav gravimetric data for the territory of Slovenia was filtered. Figure 5 depicts the deviations on individual gravimetric points before and after the filtering had been performed.

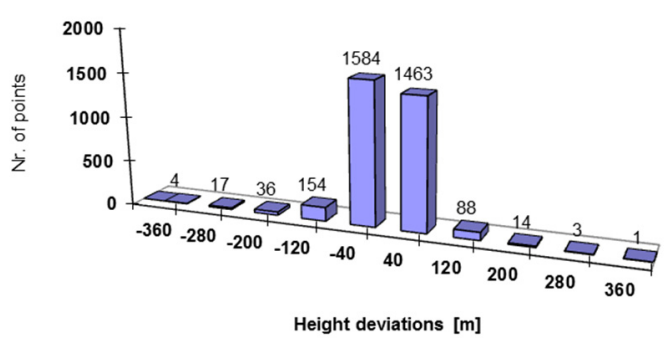

(a)

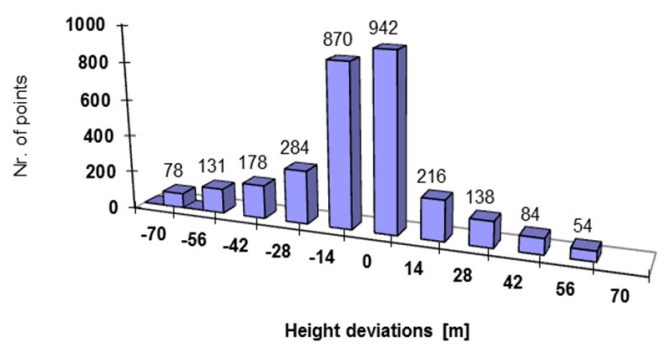

(b)

Figure 5. Height deviations in 10 size classes on: (a) the set of original Yugoslavian gravimetric data and (b) the set of filtered Yugoslavian gravimetric data. 
As we did not have the DTM1 data for the broader areas of the neighboring countries at our disposal, DTM100 was used. As this model is less precise and reliable (compared to DTM1), we considered a deviation by a height of $\pm 100 \mathrm{~m}$ as the criterion for eliminating coarse data. The data were filtered with this criterion and an additional four points were eliminated from the area of Italy and 28 points from the territory of Croatia. No coarse errors were perceived in the geolocation of the data for the territories of Austria and Hungary.

\section{Methods}

\section{Calculations of the Gravity Anomalies}

The measured gravity values need to be reduced by various corrections if one wishes to calculate the gravity anomalies. In general, the procedures for reducing the measured gravity are not standardized and differ greatly in the various geophysical texts, available (commercial) software, and scientific articles [21]. With the intention of unifying and standardizing the procedures, the United States Geological Survey and the North American Gravity Database Committee prescribed unified standard procedures for calculating gravity anomalies [22]. The essential change can be found in the introduction of the ellipsoid height into the calculations for gravity anomalies [7,13]. This was made possible with the use of global navigation satellite systems, where the heights' measurements refer to the ellipsoid.

One also needs to emphasize the terminological difference when discussing various heights [23]. With altitude or orthometric heights $(\mathrm{H})$, we talk about 'gravity anomalies'; with ellipsoid heights $(h)$, we talk about 'gravity disturbances'. The difference between the two is presented by the geoid height. If this was a constant, it would be irrelevant as to which heights were used in our calculations, but as it is a variable (for the area of Slovenia it spans between $44.16 \mathrm{~m}$ and $48.81 \mathrm{~m}$ ), it needs to be taken into account. In the physical sense, this difference is presented with the so-called indirect effect.

In further calculations, the formulae for individual corrections were used. These are known methods, formulae, and constants, at which two examples of calculating corrections have been treated separately: (a) reductions are based on heights given in the Slovene national height system (SVS2000 with the datum Trieste) and (b) reductions are based on ellipsoid heights (ellipsoid GRS80).

The theoretical or normal gravity on the ellipsoid $(\gamma)$ is calculated with the Somigliana formula [24] that refers to the GRS80 ellipsoid:

$$
\gamma_{0}=\left(a \gamma_{a} \cos ^{2} \varphi+b \gamma_{b} \sin ^{2} \varphi\right) /\left(\sqrt{a^{2} \cos ^{2} \varphi+b^{2} \sin ^{2} \varphi}\right)
$$

For the territory of Slovenia, the calculated values of normal gravity span between 980,658.36 $\mathrm{mGal}$ and 980,789.22 $\mathrm{mGal}$ (i.e., they span across 130.86 mGal on the latitudes between $45.35016^{\circ}$ and $46.97134^{\circ}$ ). This is graphically depicted in Figure 6, while the statistical data are shown in Table 2, column SLO_NG.

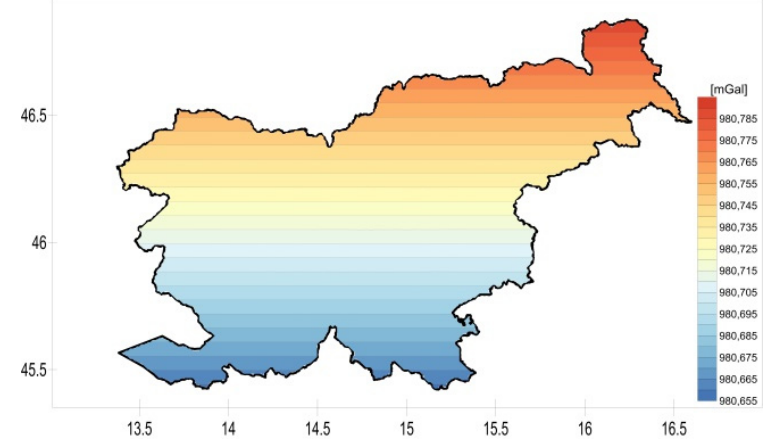

Figure 6. Normal gravity $(\gamma)$ model of Slovenia (SLO_NG). 
Table 2. Statistical data for models SLO_NG, SLO_BC, and SLO_TC.

\begin{tabular}{cccc}
\hline Statistical Indicators [mGal] & SLO_NG & SLO_BC & SLO_TC \\
\hline Min & $980,658.360$ & -1.680 & -0.030 \\
Max & $980,789.220$ & 196.040 & 37.230 \\
Span & 130.860 & 197.720 & 37.260 \\
Mean & $980,720.731$ & 55.684 & 4.185 \\
Median & $980,722.330$ & 48.545 & 2.300 \\
St. Dev. & 30.591 & 31.303 & 5.173 \\
\hline
\end{tabular}

In the procedures used to determine the gravity anomalies, the following formulas were used to calculate corrections:

- Atmospheric effect [13]:

$$
\delta g_{\text {ATM }}=0.874-9.9 \times 10^{-5} h+3.56 \times 10^{-9} h^{2}
$$

The effect is expressed in [mGal], where $h$ is height in meters.

- Formula, applicable to the GRS80 ellipsoid, was used for height correction or free-air correction [13]:

$$
\delta g_{F A}=-\left(0.3087691+0.0004398 \sin ^{2} \varphi\right) h+7.2125 \times 10^{-8} h^{2}
$$

at which height $h$ is expressed in meters, and the correction in [mGal].

- Topographic correction is divided into two parts: the Bouguer correction and the terrain correction.

- The Bouguer correction for the points on the terrain is as follows [22,25]:

$$
\delta g_{B}=2 \pi G \rho(\mu h-\lambda R)
$$

where $\mu$ and $\lambda$ are non-dimensional coefficients taken from [21]. A radius of $166.7 \mathrm{~km}$ was taken into account [25], as this is based on a sphere shaped Earth with a radius of $6371 \mathrm{~km} ; G$ (gravitational constant) $=6.673 \pm 0.01 \times 1^{-11} \mathrm{~m}^{3} \mathrm{~kg}^{-1} \mathrm{~s}^{-2}$. This constant is a recently adopted value and differs from the value given in the GRS80 ellipsoid. $h$ represents the reference height of the point. In the equation, the corrections are given in the unit $\mathrm{m} / \mathrm{s}^{2}$, which is then transformed into [mGal] by multiplying it by $10^{5}$, while $\rho$ 一the average Earth density-is $2670 \mathrm{~kg} / \mathrm{m}^{3}$ [13]. Figure 7 a depicts the calculated corrections for Slovenia, while the statistical indicators can be found in Table 2.

- The terrain corrections were calculated with TopoSK software [26]. The software enables the calculation of various terrain (topographic) influences or corrections of gravimetric quantities. The calculations are based on Pohanka's formula, which calculates the gravitational effect of the polyhedral body [27], up to the distance of the outer limit of zone O $(166.7 \mathrm{~km})$ of the Hayford-Bowie system [28]. Different resolution DEMs, with resolution increasing toward the evaluation point, and different representations (with the option of using planar or spherical approach) of the volumetric elements are used within different integration zones of the Hayford-Bowie system. In our case, DTM25 (cell size $25 \mathrm{~m} \times 25 \mathrm{~m}$ ) was used up to a distance of $250 \mathrm{~m}$, DTM100 (cell size $100 \mathrm{~m} \times 100 \mathrm{~m}$ ) from $250 \mathrm{~m}$ to $5240 \mathrm{~m}$, and DTM1000 (cell size $1000 \mathrm{~m} \times 1000 \mathrm{~m}$ or $\left.3^{\prime} \times 4.5^{\prime}\right)$ from $5240 \mathrm{~m}$ on. The calculation was performed in line with the radius around each point, which was set in advance. The constant $2670 \mathrm{~kg} / \mathrm{m}^{3}$ was adopted as the topographic density, as this should represent the average density of the rocks in the addressed area. The average value of the terrain correction was $3.03 \mathrm{mGal}$, while the standard deviation was $4.90 \mathrm{mGal}$, the minimum 
was 0.0 and the maximum $56.70 \mathrm{mGal}$ (in Austria). The dispersion and size of the terrain corrections for the territory of Slovenia is shown in Figure $7 \mathrm{~b}$.

Table 2 shows the gathered statistical data for the map (model) of normal gravities $\gamma$ in Slovenia (SLO_NG), the model of Bouguer corrections for the territory of Slovenia (SLO_BC), and the model of terrain corrections for the territory of Slovenia (SLO_TC).

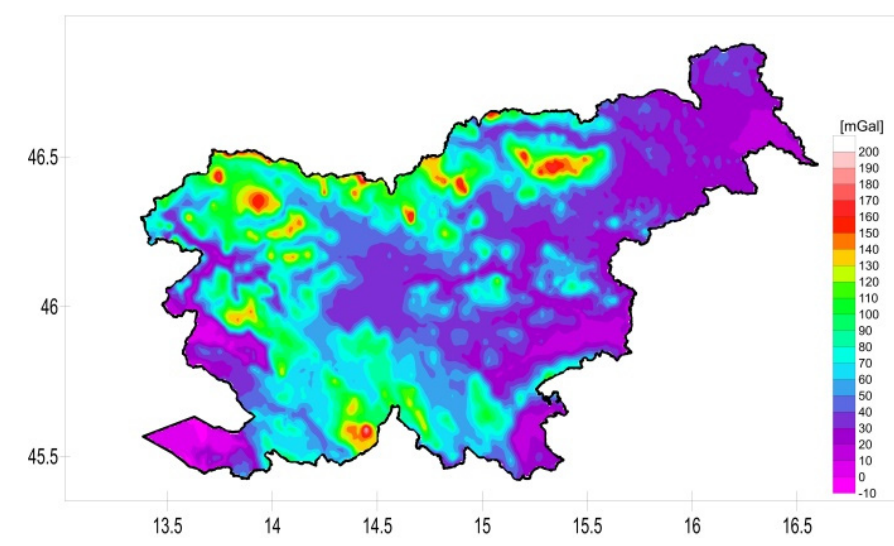

(a)



(b)

Figure 7. (a) Bouguer corrections for the territory of Slovenia (SLO_BC); (b) Terrain corrections for the territory of Slovenia (SLO_TC).

At this, we have to keep in mind that the quality of the terrain corrections depends predominantly on the quality of the used digital terrain models. When calculating the terrain corrections, the reference height can be represented by the height of the individual point for which the anomaly is calculated (i.e., GNSS/leveling, terrestrial measurements, heights digitalized from maps, ... ), or the appropriate height taken from the digital terrain model. Once we take into account the diversity of the input data of the gravimetric points, at which the geolocations and consequentially the heights of the Yugoslav gravimetric date are especially questionable, we can rightfully assume the questionable quality of the calculated terrain corrections. In the previous procedure, the coarse deviations were eliminated by filtering, which was followed by analyzing the influence they have on the final result.

\section{Results}

\subsection{Created Gravity Anomaly Maps}

The previously described corrections enabled us to calculate the various gravity anomalies. The calculations refer to individual points for which gravimetric measurements were performed and that are not homogenously distributed. In order to create new anomaly maps, they need to be shown in an appropriate grid, for which the Kriging interpolation method [29] was used, and afterward, cross validation was performed (e.g., cross validation indicators of model SLO_CBA: Mean $=-0.078$, Std. Dev. $=2.151$, RMS $=2.151$, Std. Error $=0.068$ ). The area covered by the given data and calculations is located between $45-47^{\circ} \mathrm{N}$ and $15-17^{\circ} \mathrm{E}$. For the target resolution, we chose a step at latitude $30^{\prime \prime}$ and longitude $45^{\prime \prime}$, which in nature represents a cell of approximately $1000 \mathrm{~m} \times 1000$ $\mathrm{m}$ in size.

All available gravimetric datasets were used in the creation of gravimetric anomaly maps. To calculate different anomaly maps, the following equations were used:

- $\quad$ Free air gravity anomaly:

$$
\Delta g_{F A}=g_{M E A S}-\gamma+\delta g_{A T M}+\delta g_{F A}
$$


where $g_{M E A S}$ is the observed value of the actual gravity; $\gamma$ is the normal gravity on the GRS80 ellipsoid; $\delta g_{A T M}$ is the atmospheric correction; and $\delta g_{F A}$ is the free air correction.

The anomalies were calculated for all available gravimetric points and used to create the free air anomaly map of Slovenia (SLO_FAA) shown in Figure 8a.

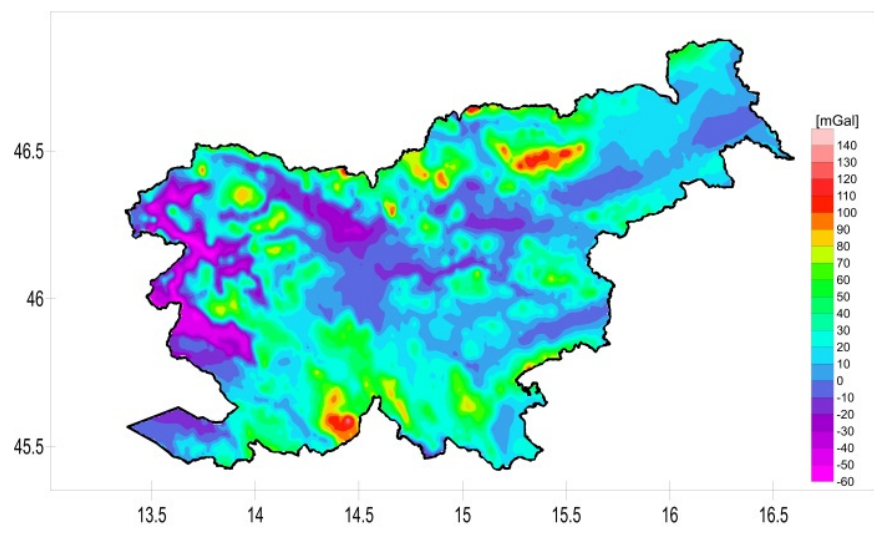

(a)

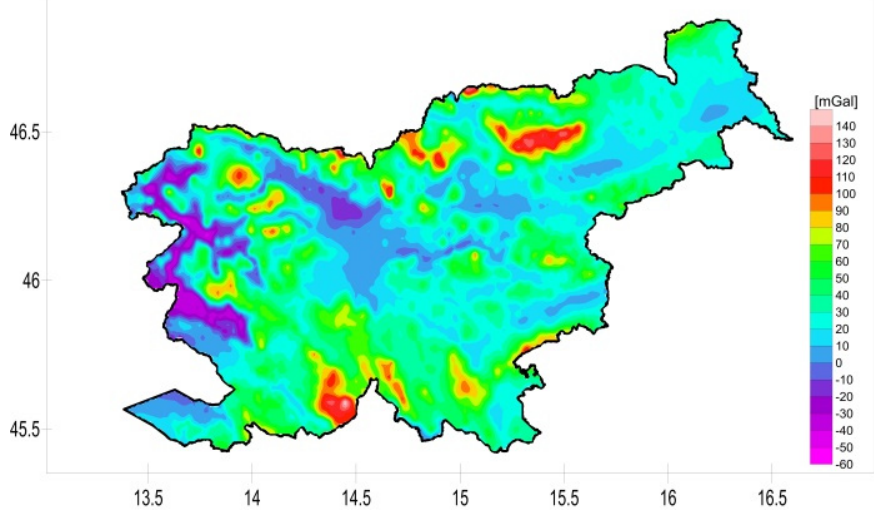

(b)

Figure 8. (a) Free air anomaly map of Slovenia (SLO_FAA); (b) Ellipsoidal free air anomaly map of Slovenia (SLO_EFAA).

- Bouguer gravity anomaly:

$$
\Delta g_{B}=g_{M E A S}-\gamma+\delta g_{A T M}+\delta g_{F A}-\delta g_{B}
$$

where $\delta g_{B}$ is the Bouguer correction. The anomalies were calculated for all available gravimetric points and used to create the Bouguer anomaly map (SLO_BA) shown in Figure 9a.



(a)

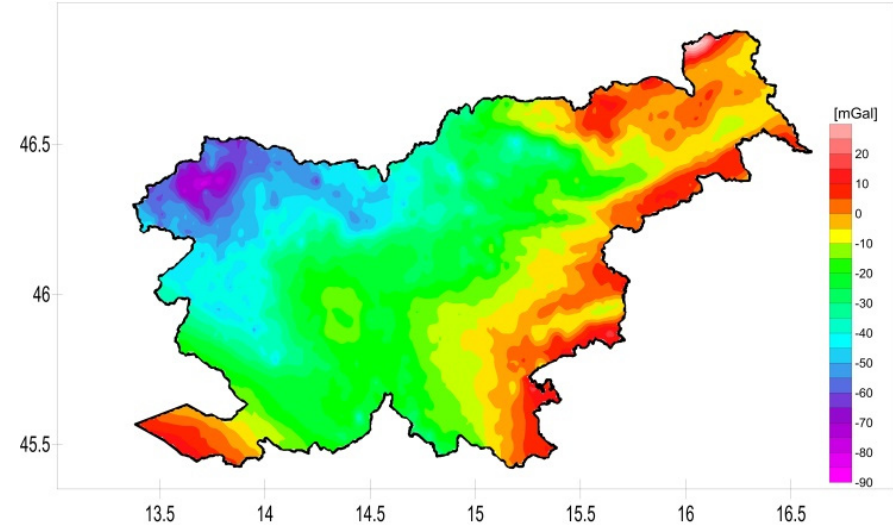

(b)

Figure 9. (a) Bouguer anomaly map of Slovenia (SLO_BA); (b) Ellipsoidal Bouguer anomaly map of Slovenia (SLO_EBA).

- Complete Bouguer gravity anomaly:

$$
\Delta g_{C B}=g_{O P Z}-\gamma+\delta g_{A T M}+\delta g_{F A}-\delta g_{B}+T C
$$

where $T C$ is the terrain correction. The complete Bouguer gravity anomaly was obtained by adding the terrain correction to the Bouguer gravity anomalies. The anomalies were calculated for all available gravimetric points and used to create the map of complete Bouguer anomalies (SLO_CBA) shown in Figure 10a. 


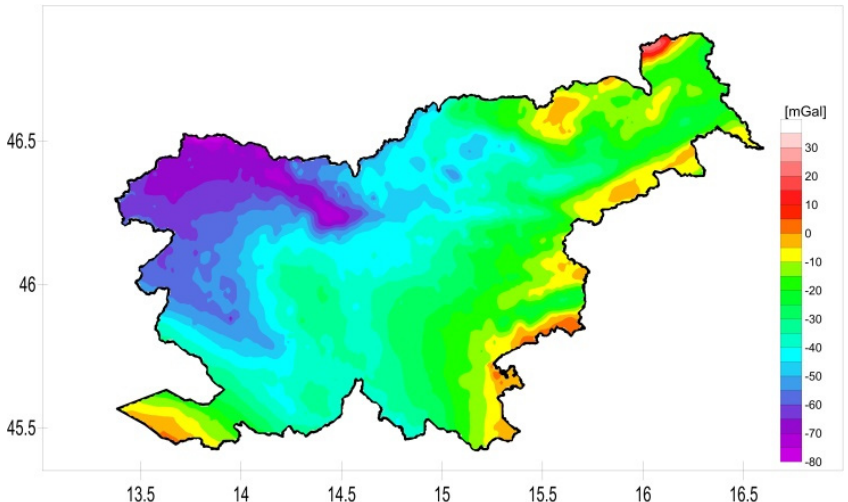

(a)

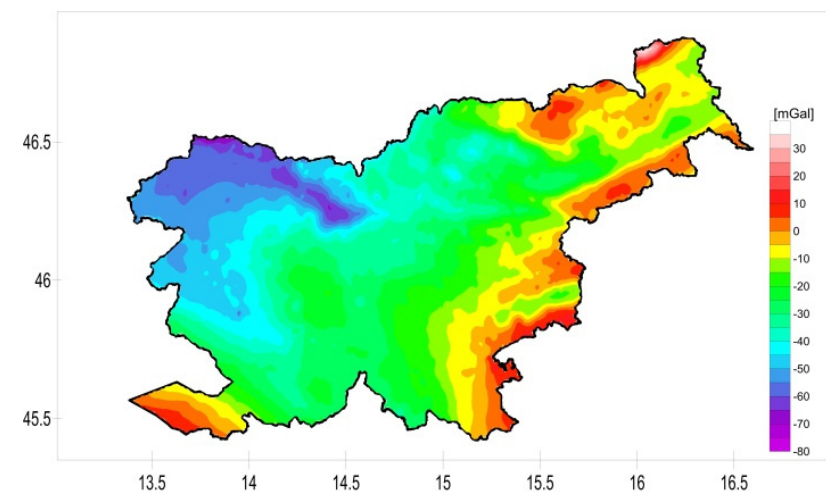

(b)

Figure 10. (a) Complete Bouguer anomaly map of Slovenia (SLO_CBA); (b) Complete ellipsoidal Bouguer anomaly map of Slovenia (SLO_ECBA).

With meaningful use of ellipsoid heights when calculating gravity anomalies, ellipsoid maps of gravimetric anomalies were also created. In accordance with the revised standards [13], the terms 'Ellipsoidal free air anomaly map of Slovenia' (SLO_EFAA) shown in Figure 8b; 'Ellipsoidal Bouguer anomaly map of Slovenia' (SLO_EBA) shown in Figure 9b; and 'Complete ellipsoidal Bouguer anomaly map of Slovenia' (SLO_ECBA) shown in Figure 10 b were used.

The statistical data of gravimetric anomalies maps (models) are gathered in Table 3 and refer to the selected area within Slovenia.

Table 3. Statistical data of gravimetric anomaly models of Slovenia.

\begin{tabular}{ccccccc}
\hline $\begin{array}{c}\text { Statistical Indicators } \\
{[\mathrm{mGal}]}\end{array}$ & SLO_FAA & SLO_EFAA & SLO_BA & SLO_EBA & SLO_CBA & SLO_ECBA \\
\hline Min & -58.620 & -44.120 & -106.030 & -96.560 & -86.620 & -77.070 \\
Max & 135.120 & 149.580 & 22.680 & 31.690 & 23.150 & 32.160 \\
Span & 193.740 & 193.700 & 128.710 & 128.250 & 109.770 & 109.230 \\
Mean & 17.878 & 32.244 & -37.806 & -28.702 & -33.621 & -24.517 \\
Median & 15.090 & 29.415 & -36.900 & -27.800 & -34.270 & -25.150 \\
St. Dev. & 26.017 & 26.078 & 21.254 & 21.142 & 17.753 & 17.652 \\
\hline
\end{tabular}

A comparison of the complete Bouguer anomaly map of Slovenia (SLO_CBA) to the complete ellipsoid Bouguer anomaly map of Slovenia (SLO_ECBA) was undertaken. The results are presented in Table 4 and shown in Figure 11a.

Table 4. Statistical indicators of the differences between the models SLO_CBA and SLO_ECBA.

\begin{tabular}{cc}
\hline Statistical Indicators [mGal] & SLO_CBA-SLO_ECBA \\
\hline Min & -9.01 \\
Max & 27.75 \\
Span & 36.760 \\
Mean & -4.918 \\
Median & -6.780 \\
St. Dev. & 5.060 \\
\hline
\end{tabular}




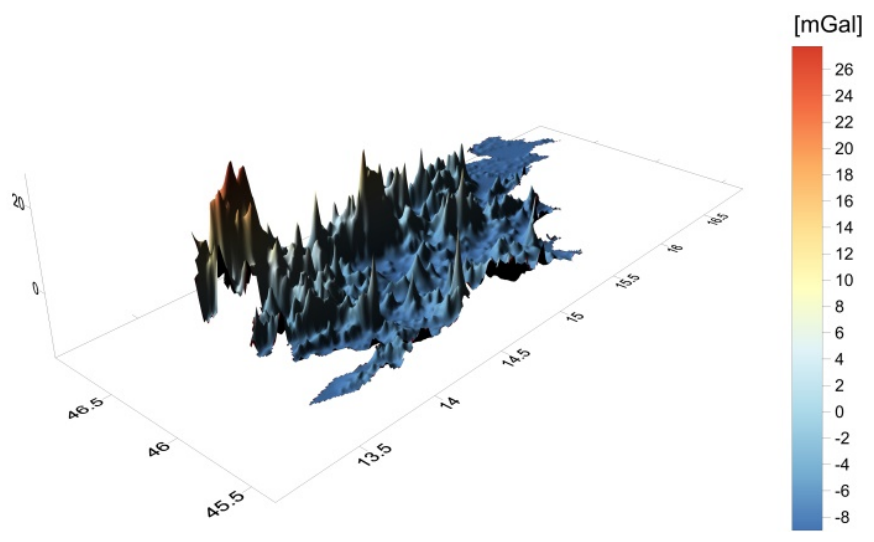

(a)

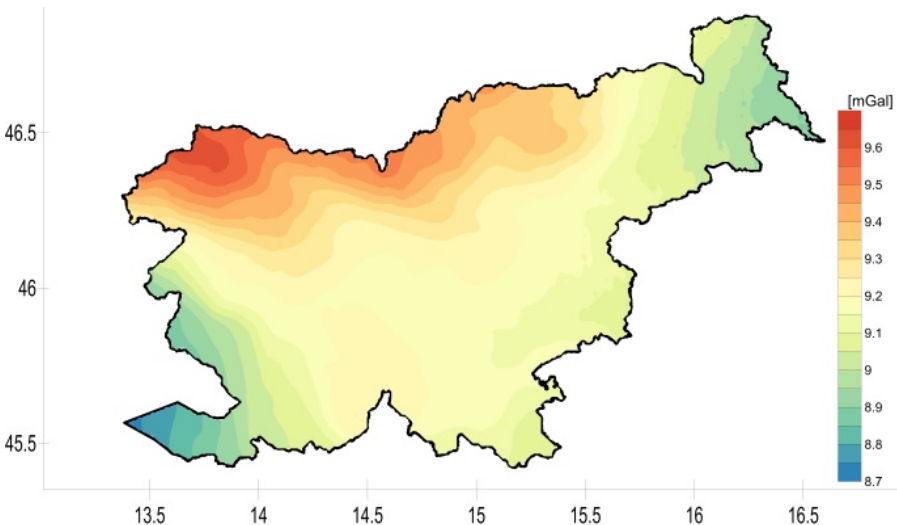

(b)

Figure 11. (a) Graphic display of the difference between the models SLO_CBA and SLO_ECBA; (b) Geophysical indirect effect map of Slovenia.

\subsection{Indirect Effect}

The indirect effect appears as a result of using various height data when defining the heights of the gravimetric points and the theoretical gravity field. It represents the influence of gravity of the masses between these two height datums, which are included in the corrections of the Bouguer plate. If we assume a constant density of the plate between them, we can calculate the correction of the indirect effect as [23]:

$$
\delta g_{I E}=(0.3086-2 \pi G \rho) \times N=0.1976 \times N
$$

where $N$ is the geoid undulation in $m$, and $\varrho$ is the average density of the Earth $\left(2670 \mathrm{~kg} / \mathrm{m}^{3}\right)$. The correction provides a value in [mGal]. Figure 11b shows the map of indirect effects for the territory of Slovenia with $0.05 \mathrm{mGal}$ isolines.

It should be emphasized that we did not pay attention to the coast and the sea (bathymetric corrections) in all of the created maps as we did not have gravimetric data for sea surfaces at our disposal, and the efficient equations when calculating the terrain corrections at sea were also not taken into account. At the sea surfaces, one should also take into account the density of water, which for observations on sea means that one needs to take into account the density of seawater $\left(1027 \mathrm{~kg} / \mathrm{m}^{3}\right)$, while for observations on fresh water, one needs to take into account the density of fresh water $\left(1000 \mathrm{~kg} / \mathrm{m}^{3}\right)$, and for observations on ice, the density of ice $\left(917 \mathrm{~kg} / \mathrm{m}^{3}\right)$. For more on this, see [12,30].

\subsection{Comparison of the Gravity Anomaly Maps for Slovenia with the Analysis of the Influence of} Gravimetric Data

The depictions were created from all available gravimetric data for the territory of Slovenia and its vicinity (data from Italy, Austria, Hungary, and Croatia). In total, 15.930 point anomalies were calculated (Figure 12a), of which 6457 were located within the territory of Slovenia while the remaining 9473 were located in the territories of neighboring countries. 


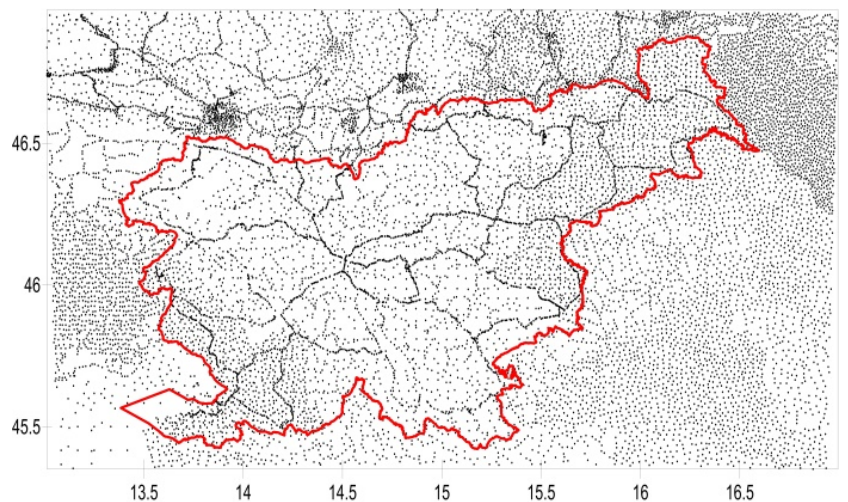

(a)



(c)

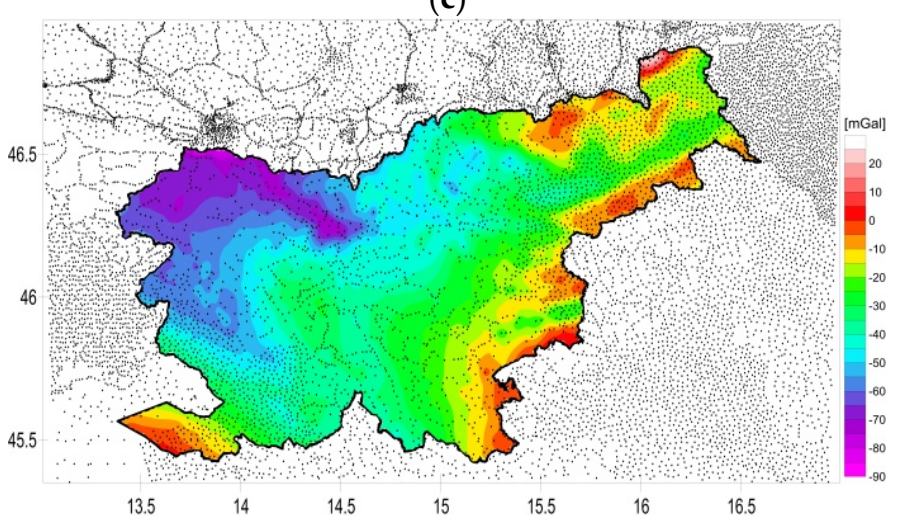

(e)



(b)

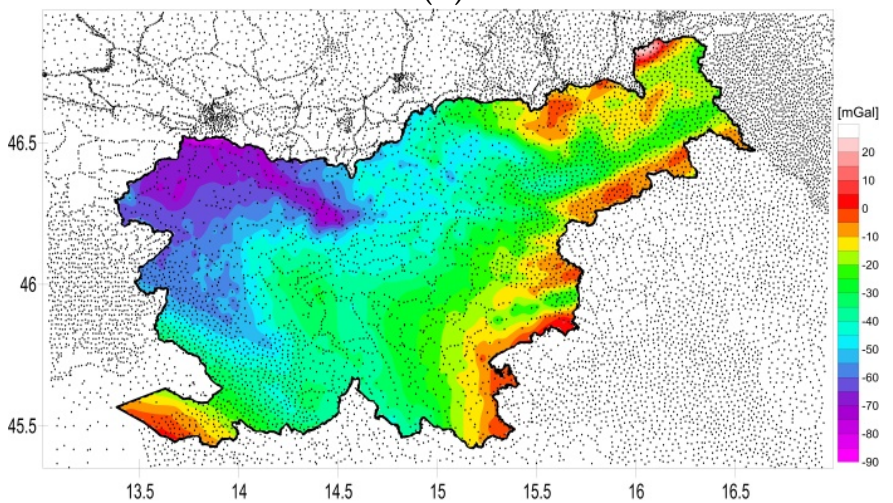

(d)

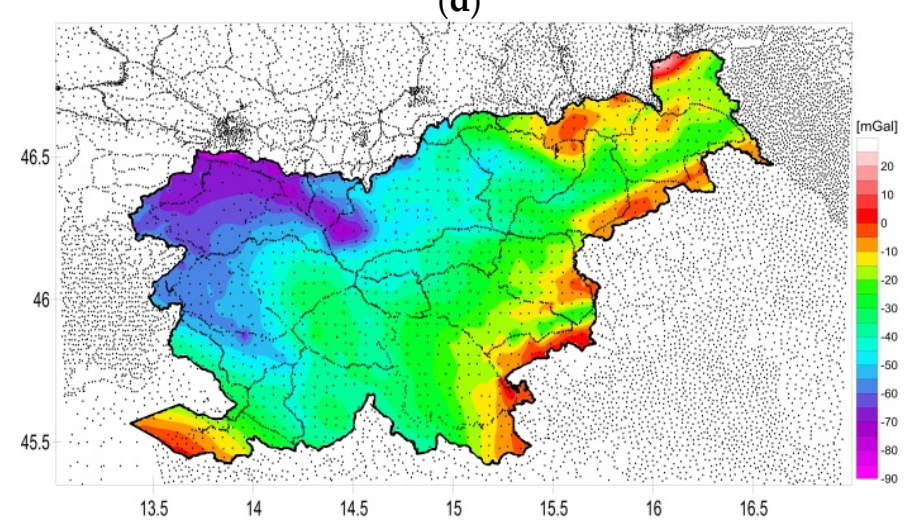

(f)

Figure 12. (a) All available gravimetric data for Slovenia and its surroundings; (b) CBA_ref; (c) CBA_all; (d) CBA_onlyYU; (e) CBA_only_filtered_YU; and (f) CBA_only_SLO.

Therefore, we had at our disposal a high number of gravimetric points, which made it possible to create maps with different input data that were used to compare the influence input data has on calculating gravity anomalies. The analysis was performed on the complete Bouguer anomaly map of Slovenia and calculations were performed with different sets of gravimetric data. The main interest was in their influence on the models and the differences between the calculated models. Various models with the following designations and input data have been created:

CBA_ref: The new gravimetric data for Slovenia (Section 2.2: C-E), the filtered old gravimetric data of the former SFRY for the territory of Slovenia and a part of Croatia (Section 2.2: A-filtered) and the gravimetric data of the border area with the neighboring countries (i.e., Italy, Austria, and Hungary (Section 2.2: B) were used (see Figure 12b). 
CBA_all: The new gravimetric data for Slovenia (Section 2.2: C-E), all old gravimetric data of the former SFRY (Section 2.2: A-before filtering) (i.e., non-filtered) as well as the gravimetric data from the neighboring countries (Section 2.2: B) were used (see Figure 12c).

CBA_only_YU: Only old gravimetric data of the former SFRY (Section 2.2: A), which was assumed to have been used in the current Bouguer anomaly map for Slovenia [3,4] created in 1972 (Figure 1a), were used. This means that the original set of unfiltered Yugoslav data and the gravimetric data from the neighboring countries (Section 2.2: B) were used (see Figure 12d).

CBA_only_filter_YU: Only filtered old gravimetric data of the former SFRY for the territory of Slovenia (Section 2.2: A-filtered) and the gravimetric data from neighboring countries were used (Section 2.2: B) (see Figure 12e).

CBA_only_SLO: All old Yugoslav data for the territory of Slovenia were eliminated and only data from the new Slovene survey (Section 2.2: C-E) and the gravimetric data from the neighboring countries (Section 2.2: B) were used (see Figure 12f).

The complete Bouguer anomaly maps (models), together with the used gravimetric points (as described above), are shown in Figure 12b-f.

As the point of interest is in the differences between the created maps, a simple comparison (subtraction of the models) was employed. With this, one can observe the actual influence of the input gravimetric datasets on the final result as the same method of calculation and interpolation had been used in all cases. The statistical data of the differences between the models are presented in Table 5 .

Table 5. Statistical characteristics of differences between models.

\begin{tabular}{lccccccc}
\hline \multicolumn{1}{c}{ Difference in the Models } & $\begin{array}{c}\text { Min } \\
{[\mathbf{m G a l}]}\end{array}$ & $\begin{array}{c}\text { Max } \\
{[\mathbf{m G a l}]}\end{array}$ & $\begin{array}{c}\text { Span } \\
{[\mathbf{m G a l}]}\end{array}$ & $\begin{array}{c}\text { Mean } \\
{[\mathrm{mGal}]}\end{array}$ & $\begin{array}{c}\text { Median } \\
{[\mathrm{mGal}]}\end{array}$ & $\begin{array}{c}\text { St. Dev } \\
{[\mathrm{mGal}]}\end{array}$ & $\begin{array}{c}\text { Figure } \\
\text { No. }\end{array}$ \\
\hline CBA_ref-CBA_all & -12.28 & 8.42 & 20.70 & 0.02 & 0.00 & 0.42 & $13 \mathrm{a}, \mathrm{b}$ \\
CBA_ref-CBA_only YU & -13.37 & 12.05 & 25.42 & 0.12 & 0.00 & 0.77 & $13 \mathrm{c}, \mathrm{d}$ \\
CBA_ref-CBA_only SLO & -13.56 & 13.11 & 26.67 & -0.04 & 0.00 & 0.71 & $13 \mathrm{e}, \mathrm{f}$ \\
CBA_only SLO-CBA_only YU & -15.91 & 15.24 & 31.15 & 0.16 & 0.00 & 1.10 & $13 \mathrm{~g}, \mathrm{~h}$ \\
CBA_only filter YU-CBA_only YU & -13.14 & 10.97 & 24.11 & 0.00 & 0.00 & 0.58 & $13 \mathrm{i}, \mathrm{j}$ \\
\hline
\end{tabular}

The differences between the models are also shown in graphic form, as this provides an insight into the spatial distribution of the changes that occur as a consequence of the various input gravimetric data. The differences are shown in Figure 13, at which the 2D outlines are shown on the left while the 3D depictions of the same models are shown on the right. The CBA_ref model was taken as the reference model. This model is the same as the complete Bouguer anomaly map SLO_CBA (Figure 10a) in which all available gravimetric data were used (i.e., the new gravimetric data of Slovenia, the filtered old gravimetric data of the former SFRY as well as the data from the neighboring countries). Figure 13a,b shows the actual influence of the eliminated (filtered) old gravimetric data of the former SFRY in relation to the reference data. The changes graphically coincide with the eliminated data (as shown in Figure 4). Figure 13c,d shows the difference that emerged in relation to reference data, if only filtered gravimetric data of the former SFRY were used (i.e., without the new gravimetric data for Slovenia). Figure 13e,f shows the difference in relation to reference data, only if the new gravimetric data for Slovenia were used (i.e., data measured after the year 2000). Figure 13g,h shows the direct difference between the models only if the old gravimetric data of the former SFRY and only the new gravimetric data for Slovenia were used. It can be seen that the changes were relatively significant (max. span $31.15 \mathrm{mGal}$, see Table 5) and spread across the entire territory. Thus, we are not dealing with a systematic shift as the changes are a consequence of the improved data quality, which has been acquired with the new gravimetric surveys. Figure 13i,j shows the direct influence of the eliminated (filtered) gravimetric data of the former SFRY, which confirms the usage of this version as the differences spanned across $24.11 \mathrm{mGal}$. Of course, this difference was extremely similar to the difference depicted in Figure 13a,b. 


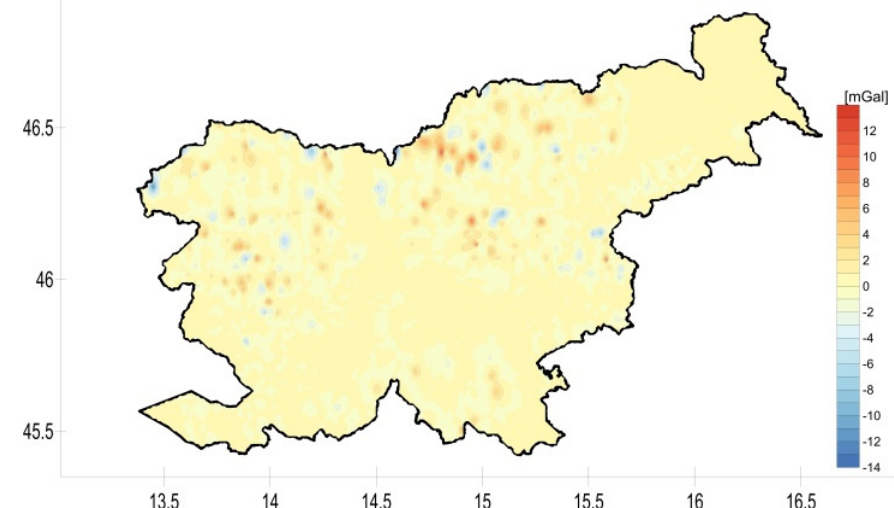

(a)



(c)

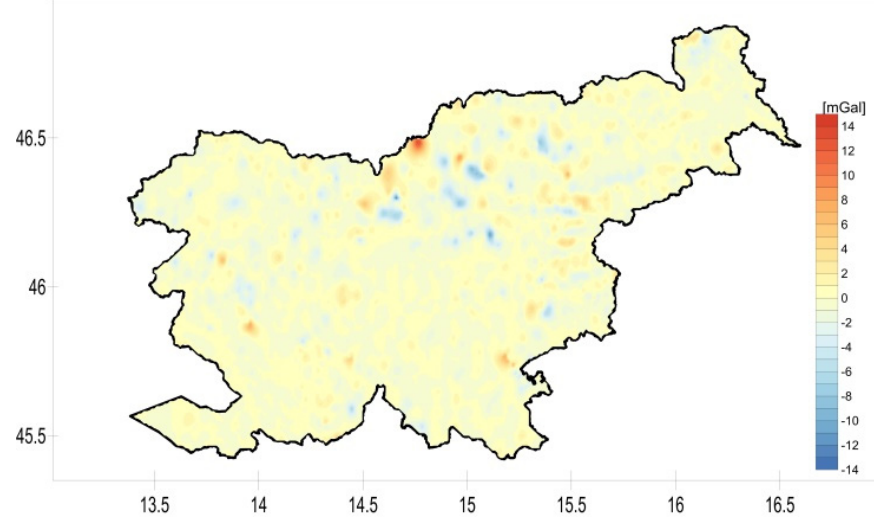

(e)

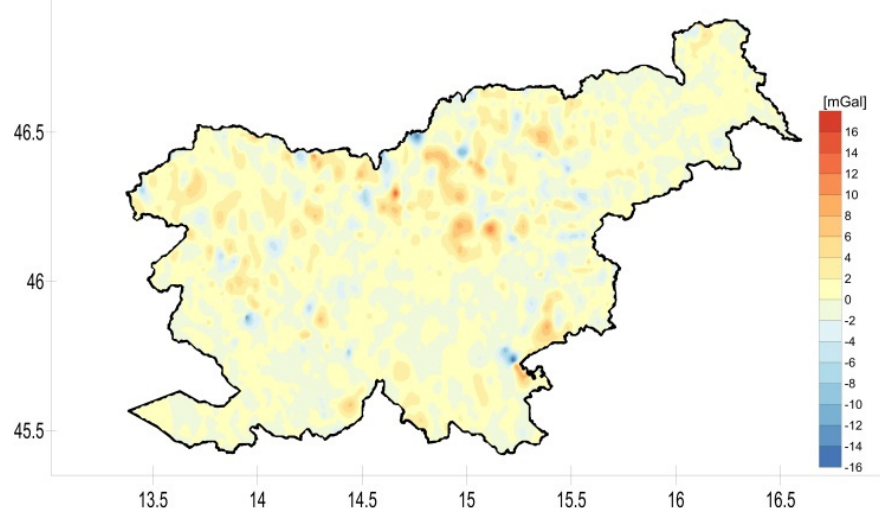

(g)

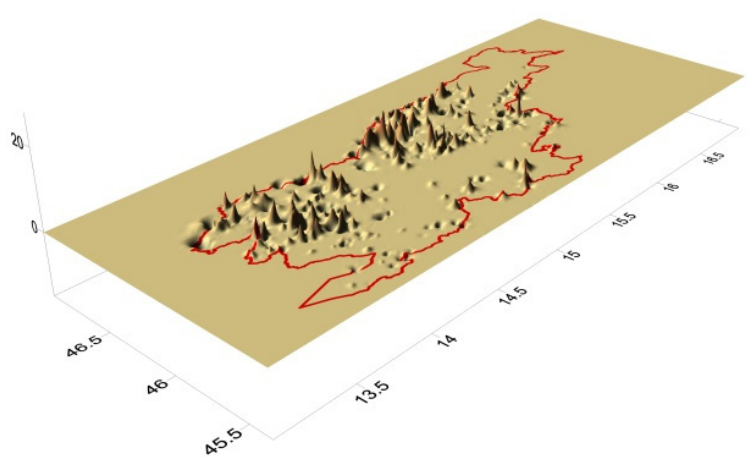

(b)

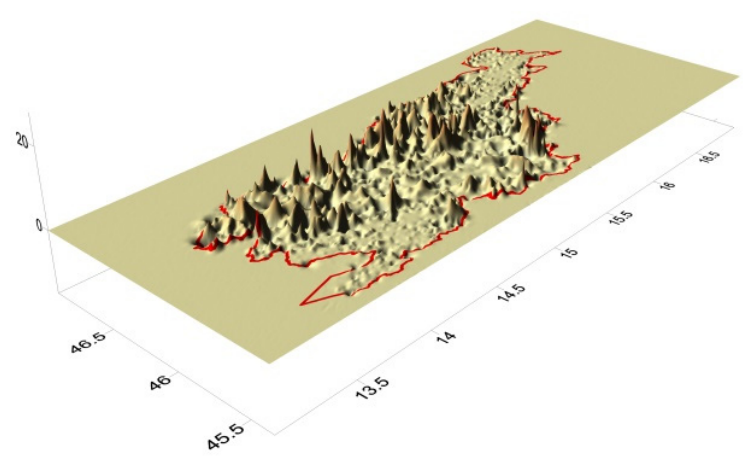

(d)

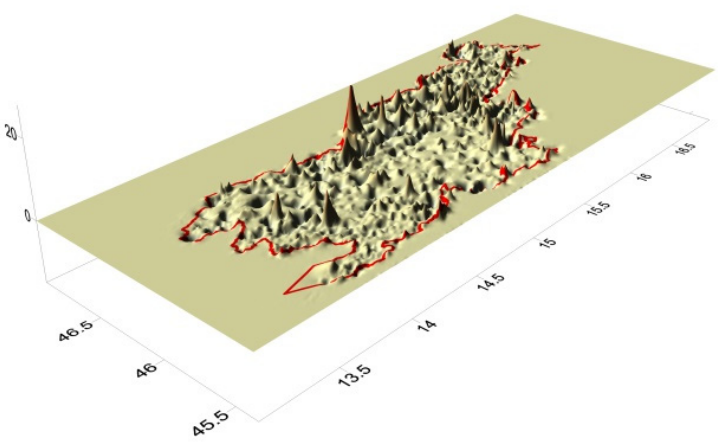

(f)

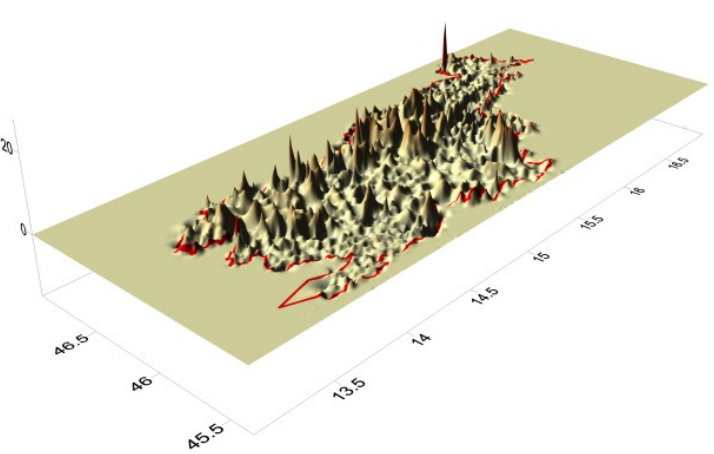

(h)

Figure 13. Cont. 


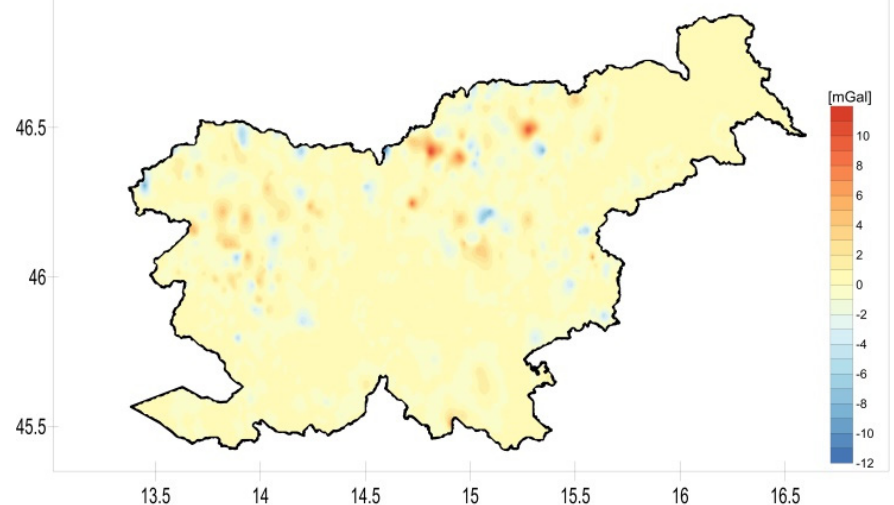

(i)

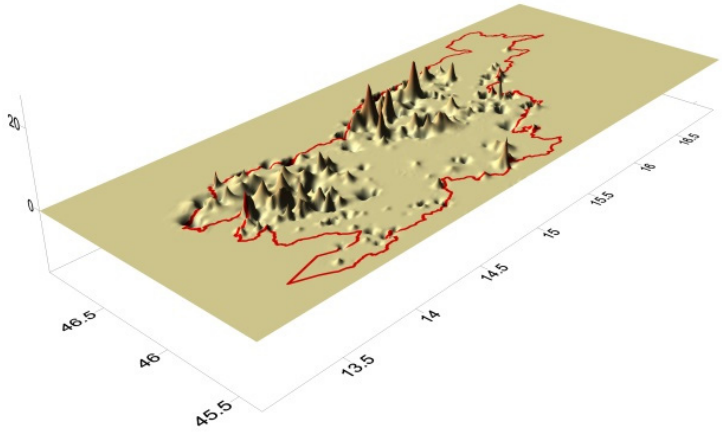

(j)

Figure 13. The differences between the models, $2 \mathrm{D}$ view on the left, $3 \mathrm{D}$ view on the right; $(\mathbf{a}, \mathbf{b}) \mathrm{CBA}$ ref-CBA All; (c,d) CBA ref-CBA only YU; (e,f) CBA ref-CBA only SLO; $(\mathbf{g}, \mathbf{h})$ CBA only SLO-CBA only YU; $(\mathbf{i}, \mathbf{j})$ CBA only filtered YU—CBA only YU.

\section{Conclusions}

The depicted Bouguer anomaly map of Slovenia was recalculated for the first time in decades. Since the last map has been created, the methodology for calculating gravity anomalies has been updated and revised. The 'input' data that is needed to create the gravity anomaly map has also improved significantly. However, most of all, digital terrain models have been greatly improved and higher quality gravimetric data are at our disposal. These data do not merely refer to the territory of Slovenia, but also encompasses areas within neighboring countries. We assumed there was no data for neighboring countries (with the exception of Croatia) available when the last gravity anomaly was calculated. Nowadays, there are many efficient software, which enables relatively fast calculation of all data.

All available gravimetric data for the territory of Slovenia and its surroundings were used to create the described maps. In total, 15,930 point anomalies were calculated, of which 6457 were located within the territory of Slovenia while the remaining 9473 were located in the territories of neighboring countries. As described in the text, only those points from the existing set of Yugoslav gravimetric data were eliminated that were determined as showing a gross error and even this was performed based merely on their geolocation (cross-section with DTM). Of course, the question arises as to whether gross errors were not present in this dataset, but also in the gravity values, and whether these should also be eliminated from future procedures.

The interpolation method used has a significant influence on the final product. In the creation of the final appropriate grid (from non-homogenously dispersed points), one has the possibility of using a number of different interpolation methods. The differences between them are not presented in this article, however, they are present and further analysis should be performed on this topic.

The comparison of the various maps and the analysis of the influence of input gravimetric data indicates that the new gravimetric data of Slovenia has a significant influence on the creation of the gravimetric anomaly map for Slovenia. It is also important that the input data used in future map creation are reliable (i.e., has no gross errors), as our data sample showed that the variations in the final values of the various models surpassed $30 \mathrm{mGal}$. Thus, it is essential that only high-quality data are used in the creation of gravimetric anomaly maps. The preparation, cleaning/filtering, and analysis of data are essential parts of the process, as this enables us to create high quality models.

After several decades, we have obtained a new gravimetric anomaly map for the territory of Slovenia, a map based on modern calculation procedures and high quality input data, gravimetric as well as DTM. We assume that the new Bouguer anomaly map 
for the territory of Slovenia is of higher quality because of this and a better reflection of the field of gravity. As such, it enables better interpretations of the phenomena.

Author Contributions: K.M. and O.O. designed the research; K.M. performed the research; K.M., O.O. and B.K. wrote the paper. All authors have read and agreed to the published version of the manuscript.

Funding: This research received no external funding.

Institutional Review Board Statement: Not applicable.

Informed Consent Statement: Not applicable.

Data Availability Statement: The datasets generated and/or analyzed during the study are available from the corresponding author upon reasonable request.

Acknowledgments: The authors acknowledge the financial support from the Slovenian Research Agency (research core funding No. P2-0227 Geoinformational structure and sustainable spatial development in Slovenia).

Conflicts of Interest: The authors declare no conflict of interest.

\section{References}

1. Koler, B.; Medved, K.; Kuhar, M. Projekt nove gravimetrične mreže 1. reda republike Slovenije (The Project of the New Gravimetric Network of the 1st Order of the Republic of Slovenia). Geod. Vestn. 2006, 50, 451-460. (In Slovenian)

2. Bilibajkič, P.; Mladenovič, M.; Mujagič, S.; Rimac, I. Explanation for the Gravity Map of SFR Yugoslavia-Bouguer Anomalies-1:500 000; Federal Geological Institute Belgrade: Belgrade, Serbia, 1979.

3. Čibej, B. Regional Gravity Map of Slovenia 1966-1967; Unpublished Report; Geological Survey of Slovenia: Ljubljana, Slovenia, 1967. (In Slovenian)

4. Stopar, R. Map of the Bouguer anomalies. In Geological Atlas of Slovenia; Novak, M., Rman, N., Eds.; Geological Survey of Slovenia: Ljubljana, Slovenia, 2016; pp. 20-21. (In Slovenian)

5. Gosar, A. Mohorovičić discontinuity depth. In Geological Atlas of Slovenia; Novak, M., Rman, N., Eds.; Geological Survey of Slovenia: Ljubljana, Slovenia, 2016; pp. 18-19. (In Slovenian)

6. De Marchi, P.A.; Ghidella, M.E.; Tocho, C.N. Analysis of Different Methodologies to Calculate Bouguer Gravity Anomalies in the Argentine Continental Margin. Geosciences 2014, 4, 33-41.

7. Meurers, B.; Ruess, D. A New Bouguer Gravity Map of Austria. Austrian J. Earth Sci. 2009, 102, 62-70.

8. Kiss, J. Bouguer Anomaly Map of Hungary. Geophys. Trans. 2006, 45, 99-104.

9. Tiberti, M.; Orlando, L.; Di Bucci, D.; Bernabini, M.; Parotto, M. Gravity Anomaly Map and Crustal Model of the Central-Southern Apennines (Italy). J. Geodyn. 2005, 40, 73-91. [CrossRef]

10. Tassis, G.A.; Grigoriadis, V.; Tziavos, I.; Tsokas, G.N.; Papazachos, C.; Vasiljević, I. A New Bouguer Gravity Anomaly Field for the Adriatic Sea and its Application for the Study of the Crustal and Upper Mantle Structure. J. Geodyn. 2013, 66, 38-52. [CrossRef]

11. Varga, M.; Stipčević, J. Gravity anomaly models with geophysical interpretation of the Republic of Croatia, including Adriatic and Dinarides regions. Geophys. J. Int. 2021, 226, 2189-2199.

12. Zahorec, P.; Papco, J.; Pasteka, R.; Bielik, M.; Sylvain, B.; Braitenberg, C.; Ebbing, J.; Gabriel, G.; Gosar, A.; Grand, A.; et al. The First Pan-Alpine Surface-gravity Database, a Modern Compilation that Crosses Frontiers. Earth Syst. Sci. Data 2021, 13, $2165-2209$. [CrossRef]

13. Hinze, W.J.; Aiken, C.; Brozena, J.M.; Coakley, B.J.; Dater, D.; Flanagan, G.P.; Forsberg, R.; Hildenbrand, T.G.; Keller, G.R.; Kellogg, J.W.; et al. New Standards for Reducing Gravity Data: The North American Gravity Database. Geophysics 2005, 70, 25-32. [CrossRef]

14. Farr, T.G.; Rosen, P.A.; Caro, E.; Crippen, R.; Duren, R.; Hensley, S.; Kobrick, M.; Paller, M.; Rodriguez, E.; Roth, L.; et al. The Shuttle Radar Topography Mission. Rev. Geophys. 2007, 45, RG2004. [CrossRef]

15. Berk, S.; Komadina, Ž. Local to ETRS89 Datum Transformation for Slovenia: Triangle-Based Transformation Using Virtual Tie Points. Surv. Rev. 2013, 45, 25-34. [CrossRef]

16. CRS-EU: IT_ROMA40. Available online: http://crs.bkg.bund.de/crseu/crs/eu-countrysel.php?country=IT\#StartCE (accessed on 3 October 2021).

17. Koler, B.; Medved, K.; Kuhar, M. The New Fundamental Gravimetric Network of Slovenia. Acta Geod. Geophys. Hung. 2012, 47, 271-286. [CrossRef]

18. Medved, K.; Kuhar, M.; Stopar, B.; Koler, B. Izravnava opazovanj v osnovni gravimetrični mreži Republike Slovenije (Levelling Observations in the Fundamental Gravimetric Network of the Republic of Slovenia). Geod. Vestn. 2009, 53, 223-238. (In Slovenian)

19. Koler, B.; Stopar, B.; Sterle, O.; Urbančič, T.; Medved, K. Nov slovenski višinski sistem (New Slovene Height System). Geod. Vestn. 2019, 63, 27-40. (In Slovenian) [CrossRef]

20. Medved, K.; Kuhar, M.; Koler, B. Regional Gravimetric Survey of Central Slovenia. Measurement 2019, 136, 395-404. [CrossRef] 
21. Holom, D.I.; Oldow, J.S. Gravity Reduction Spreadsheet to Calculate the Bouguer Anomaly Using Standardized Methods and Constants. Geosphere 2007, 3, 86-90. [CrossRef]

22. NGIA 2008. Gravity Stations Data Format and Anomaly Computations. National Geospatial-Intelligence Agency, Office of Geoint Sciences. Available online: https://www5.obs-mip.fr/wp-content-omp/uploads/sites/46/2017/10/computations.pdf (accessed on 11 October 2021).

23. Hackney, I.R.; Featherstone, W. Geodetic Versus Geophysical Perspectives of the 'Gravity Anomaly'. Geophys. J. Int. 2003, 154, 35-43. [CrossRef]

24. Somigliana, C. Teoria generale del campo gravitazionale dell'ellissoide di rotazione. Mem. Soc. Astron. Ital. 1929, 4, 425.

25. LaFehr, T.R. An Exact Solution for the Gravity Curvature (Bullard B) Correction. Geophysics 1991, 56, 1179-1184. [CrossRef]

26. Zahorec, P.; Marušiak, I.; Mikuška, J.; Pašteka, R.; Papčo, J. Understanding the Bouguer Anomaly, Numerical Calculation of Terrain Correction within the Bouguer Anomaly Evaluation (Program Toposk); Roman Pašteka, R., Mikuška, J., Meurers, B., Eds.; Understanding the Bouguer Anomaly: A Gravimetry Puzzle; Elsevier: Amsterdam, The Netherlands, 2017; pp. 79-92. ISBN 978-0-12-812913-5.

27. Pohánka, V. Optimum expression for computation of the gravity field of a homogeneous polyhedral body. Geophys. Prospect. 1988, 36, 733-751. [CrossRef]

28. Hayford, J.F.; Bowie, W. The Effect of Topography and Isostatic Compensation Uponthe Intensity of Gravity; U.S. Coast and Geodetic Survey: Washington, DC, USA, 1912.

29. Oliver, M.A.; Webster, R. Kriging: A method of interpolation for geographical informationsystems. Int. J. Geogr. Inf. Syst. 1990, 4, 313-332. [CrossRef]

30. Nowell, D. Gravity Terrain Corrections-An Overview. J. Appl. Geophys. 1999, 42, 117-134. [CrossRef] 